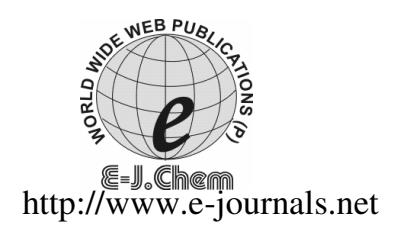

ISSN: 0973-4945; CODEN ECJHAO

E-Journal of Chemistry 2011, 8(1), 167-179

\title{
Evaluation of Pharmaceutical Quality of Mesalamine Delayed Release Tablets Using a New High Sensitivity Reversed-Phase UPLC Method for its Genotoxic/Aniline Impurity
}

\author{
RAKSHIT KANUBHAI TRIVEDI* and MUKESH C. PATEL
}

\author{
*Analytical Research and Development, Integrated Product Development \\ Dr. Reddy's Laboratories Ltd., Bachupally, Hyderabad-500 072, India \\ P.S. Science and H.D. Patel Arts College \\ S.V. Campus, Kadi-382 715, Gujarat, India \\ triveditr@yahoo.com
}

Received 16 May 2010; Revised 25 August 2010; Accepted 20 October 2010

\begin{abstract}
A reversed phase ultra performance liquid chromatography (UPLC) method was developed and validated for the quantification of aniline in mesalamine delayed-release tablets. The optimization of the experimental condition was carried out considering some important requirements like, detection limit, short run time and reproducibility. In the present study, isocratic reversed-phase UPLC method was developed for determination and separation of aniline from the drug product. The drug and impurity are well separated by using a reversed phase (Reprosil Gold C18$\mathrm{XBD}$ ) column and mobile phase comprising of buffer $\mathrm{pH} 6.0$ and acetonitrile in the ratio of 90:10 v/v. Other UPLC parameters which were optimised are flow rate, 0.5 $\mathrm{mL} / \mathrm{min}$; detection wavelength, $200 \mathrm{~nm}$; column oven temperature, $50{ }^{\circ} \mathrm{C}$ and injection volume $7 \mu \mathrm{L}$. Stability indicating capability was also established by forced degradation experiments. The method was validated as per ICH guideline. LOQ (limit of quantification) concentration $(18 \mathrm{ng} / \mathrm{mL})$ was found precise with RSD of less than $2 \%$. In essence, the present study provides an improved low detection limit and lower run time for evaluation of pharmaceutical quality of mesalamine delayedrelease formulation. Moreover, the developed method was also successfully applied for quantification of aniline in mesalamine delayed-release formulation. The same method can also be used for determination of aniline from drug substances.
\end{abstract}

Keywords: Mesalamine, 5-Aminosalicylic acid, Aniline, Genotoxicity, UPLC.

\section{Introduction}

Mesalamine (5-aminosalicylic acid, 5-ASA), a therapeutically active moiety of Sulfasalazine $^{1-3}$ is routinely employed in the treatment of inflammatory bowel disease like 
ulcerative colitis and Crohn's disease. Orally administrated mesalamine is rapidly and almost completely absorbed from the small intestine ${ }^{4-6}$. Mesalamine formulations which are able to deliver the intact drug to the lower intestine are nowadays successfully used ${ }^{7-8}$. The purity evaluation of mesalamine in drug product by determination of related substances is a critical step in examination of the safety and quality of the drug product. Aniline is the critical genotoxic impurity to be considered for mesalamine drug substance and its drug product. The chemical structure and UV spectrum of mesalamine and aniline are shown in Figure 1.

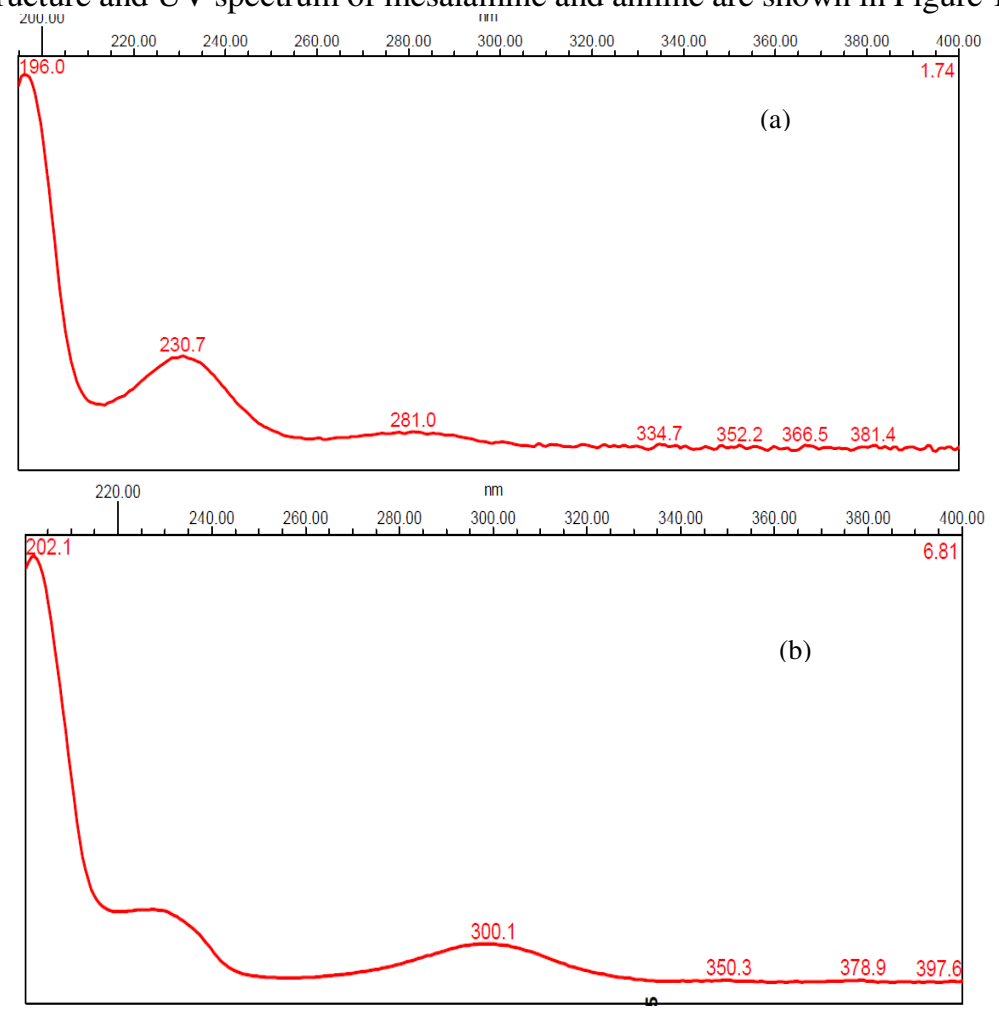

Figure 1. UV spectra of (a) aniline and (b) mesalamine

Moreover, recently the US-FDA has also published draft guidance for 'the genotoxic and carcinogenic impurities in drug substances and drug products" ${ }^{\prime}$. This emphasises the importance of controlling aniline impurity in drug substances and in drug product as well.

A genotoxic activity of aniline and its metabolites and their relationship to the carcinogenicity of aniline in the spleen of rats was reported ${ }^{10}$ by Ernst and Bernd. Potent genotoxicity of aminophenylnorharman, formed from aniline in the liver of gpt delta transgenic mouse was reported ${ }^{11}$ by Ken-ichi Masumura et al. Carcinogenicity of aminophenylnorharman, formed from aniline in F344 rats had been reported ${ }^{12}$ by Toshihiko Kawamori et al. A few analytical methods has also been reported for quantification of aniline such as spectrometric ${ }^{13}$, azo-dye formation ${ }^{14}$, fluorescence ${ }^{15,16}$, alternating-current oscillopolarographic titration ${ }^{17}$, NIR spectroscopy $^{18}$, GC $^{19}$, HPLC $^{20,21}$ and LCMS $^{22,23}$.

Aniline determination in mesalamine drug substance by GC is official in US Pharmacopeia $^{24}$ and by HPLC is official in British Pharmacopeia ${ }^{25}$. The comprehensive literatures survey revealed that the HPLC methods used for determination of quality of 
mesalamine drug substance have low sensitivity, high LOQ and long run time. Moreover, these reported methods have lack of suitable procedure for quantification and estimation of aniline. According to our literature survey, no UPLC method has yet been reported for the determination and quantification of aniline from mesalamine delayed-release tables. Thus, the aim of the present work was to develop and validate a reversed phase UPLC method with lower LOQ for the quantification of aniline in delayed release mesalamine formulation.

\section{Experimental}

Mesalamine delayed-release tablets, placebo and aniline impurity standard (purity 98.7\%) were provided by Dr. Reddy's Laboratory Ltd., Hyderabad. Acetonitrile of HPLC grade was obtained from J.T.Baker (NJ., USA), HPLC grade 1-octane sulphonic acid sodium salt was obtained from RANKEM (RFCL ltd., Delhi, India), di-potassium hydrogen orthophosphate purified, GR grade orthophosphoric acid, GR grade sodium hydroxide pallets and GR grade hydrochloric acid were obtained from Merck (Mumbai, India). $0.2 \mu \mathrm{m}$ nylon 66 membrane filter and $0.2 \mu \mathrm{m}$ nylon syringe filter was purchased from Pall life science ltd. (India). 0.2 $\mu \mathrm{m}$ PVDF syringe filter was purchased from Millipore (India). Ultra pure water (resistivity $18.2 \mathrm{M} \Omega \mathrm{cm}$ ) generated by a Milli-Q system (Millipore).

\section{Buffer preparation}

$1.74 \mathrm{~g}$ of di-potassium hydrogen orthophosphate $\left(\mathrm{K}_{2} \mathrm{HPO}_{4}\right)$ and $2.2 \mathrm{~g}$ of 1-octane sulphonic acid sodium salt was dissolved in one litre of milli-Q water. The $\mathrm{pH}$ of this solution was adjusted to 6.0 with orthophosphoric acid and then filtered through $0.2 \mu \mathrm{m}$ pall nylon membrane filter. The buffer preparation was found stable with respect to $\mathrm{pH}$ and visual clarity up to $48 \mathrm{~h}$.

\section{Chromatographic system}

Analyses were performed on Acquity ${ }^{\mathrm{TM}}$ UPLC system (Waters, Milford, USA), consisting of a binary solvent manager, sample manager and PDA (photo diode array) detector. System control, data collection and data processing were accomplished using Waters Empower- $2^{\mathrm{TM}}$ chromatography data software. The chromatographic condition was optimized using a column Reprosil Gold 100, C18-XBD $50 \mathrm{~mm}$ x $2.0 \mathrm{~mm}, 1.8 \mu \mathrm{m}$. Mobile phase was a mixture of buffer $(\mathrm{pH} 6.0)$ and acetonitrile at a ratio of $900: 100(\mathrm{v} / \mathrm{v})$ respectively. It was filtered through $0.2 \mu$ nylon filter and degassed before use. The separation of aniline from mesalamine was achieved by isocratic elution. The injection volume was $7 \mu \mathrm{L}$ and flow rate was $0.5 \mathrm{~mL} / \mathrm{min}$. The detection was carried out at $200 \mathrm{~nm}$ and column oven temperature was set at $50{ }^{\circ} \mathrm{C}$. The stress degraded samples and the solution stability samples were analyzed using a PDA detector covering the range of 195-400 nm. 1N hydrochloric acid and 1N sodium hydroxide solution in the ratio of 50:50 (v/v) was mixed and used as a diluent.

\section{Impurity standard solution preparation}

Impurity standard solution was prepared by dissolving standard substances in methanol to obtained solution containing $7.5 \mu \mathrm{g} / \mathrm{mL}$ of aniline in methanol. Five millilitres of $7.5 \mu \mathrm{g} / \mathrm{mL}$ of aniline solution was transferred to $250 \mathrm{~mL}$ volumetric flask, diluted to volume with the diluent and mixed well.

\section{Sample solution preparation}

Twenty tablets were crushed to fine powder. An accurately weighed portion of the powder equivalent to $750 \mathrm{mg}$ of mesalamine was taken in $25 \mathrm{~mL}$ volumetric flask. About $12.5 \mathrm{~mL}$ of $1 \mathrm{~N}$ hydrochloric acid was added to this flask and sonicated in an ultrasonic bath for $20 \mathrm{~min}$. 
This solution was then diluted up to the mark with $1 \mathrm{~N}$ sodium hydroxide solution and mixed well. It was then filtered through $0.2 \mu$ PVDF syringe filter and the filtrate was collected after discarding first few millilitres.

\section{Method validation}

System suitability

System suitability parameters were measured so as to verify the system performance. Standard preparation was consider for the system suitability. All important characteristics including capacity factor, peak tailing and theoretical plate number were measured. The similarity factor for the peak of aniline in the duplicate standard preparation was measured. Related standard deviation for the peak areas of aniline for five replicate (standard solution) injections was also measured. All these system suitability parameters covered the system, method and column performance.

\section{Specificity}

Forced degradation studies were performed to demonstrate selectivity and stability indicating capability of the proposed method. The powdered sample of tablets was exposed at the following conditions; acidic $\left(1 \mathrm{~N} \mathrm{HCl}, 60{ }^{\circ} \mathrm{C}, 6 \mathrm{~h}\right.$. $)$, alkaline $\left(1 \mathrm{~N} \mathrm{NaOH}, 60{ }^{\circ} \mathrm{C}, 6 \mathrm{~h}\right.$. $)$, strong oxidizing $\left(6 \% \mathrm{H}_{2} \mathrm{O}_{2}, 60{ }^{\circ} \mathrm{C}, 6 \mathrm{~h}\right.$.), hydrolysis (water, $60{ }^{\circ} \mathrm{C}, 6 \mathrm{~h}$.), thermal $\left(105{ }^{\circ} \mathrm{C}\right.$, $12 \mathrm{~h}$.), humidity $\left(25^{\circ} \mathrm{C}, 90 \% \mathrm{RH}, 7\right.$ days), sunlight (for 7 days), UV light (short and longer wavelengths). Also, placebo of tablets was exposed to above all stress conditions to identify source of degradation peaks. The entire exposed samples were analyzed by the proposed method with photo diode array detector.

\section{Precision}

Precision was investigated using sample preparation procedure for six real samples (with spiked impurity in standard concentration level) of tablets and analyzing by proposed method. Intermediate precision study was performed with different column, different instrument and different day by another analyst. Precision was also performed at LOQ and $100 \%$ of standard concentration level. The mean of percentage impurity $(n=6)$ and the relative standard deviation was calculated for aniline impurity.

\section{Accuracy}

To confirm the accuracy of the proposed method, recovery experiments were carried out by standard addition technique. Six different levels (LOQ, 50\%, 70\%, 100\%, 130\% and 150\%) of impurity standard were added to pre-analyzed tablet samples in triplicate. The percentage recoveries of aniline at each level (LOQ to $150 \%$ of standard concentration) and each replicate were determined. The mean of percentage recoveries $(n=18)$ and the relative standard deviation was calculated.

\section{Limit of detection (LOD) and limit of quantification $(L O Q)$}

The LOD and LOQ of aniline impurity were determined by using signal to noise ratio method as defined in International Conference on Harmonization (ICH) guideline ${ }^{26}$. Increasingly dilute solution of aniline impurity was injected into the chromatograph and signal to noise $(\mathrm{S} / \mathrm{N})$ ratio was calculated at each concentration.

\section{Linearity}

Linearity was demonstrated from LOQ to $150 \%$ of standard concentration using minimum seven calibration levels (LOQ, 25\%, 50\%, 75\%, 100\%, 125\% and 150\%) for aniline impurity 
standard. The method of linear regression was used for data evaluation. Peak area of standard compound was plotted against respective concentrations. Linearity was described by regression equation, correlation coefficient and $\mathrm{Y}$-intercept bias.

\section{Robustness}

The robustness as a measure of method capacity to remain unaffected by small, but deliberate changes in chromatographic conditions was studied by testing influence of small changes in flow rate $( \pm 0.05 \mathrm{~mL} / \mathrm{min})$, column oven temperature $\left(45^{\circ} \mathrm{C}\right.$ to $\left.55^{\circ} \mathrm{C}\right)$ and $\mathrm{pH}$ of buffer $(\mathrm{pH} 5.9$ to $\mathrm{pH}$ 6.1). System suitability parameters were measured for above all experiments.

\section{Stability of standard and sample preparation}

Stability of standard and sample solution was established by storage of sample solution (duplicate preparation) and standard solution at ambient temperature for $20 \mathrm{~h}$. Sample solution stability was demonstrated by spiking impurity standard in pre-analyzed tablet sample. Standard and sample solutions were re-analyzed in between duration and after $20 \mathrm{~h}$. Percentage difference were calculated against fresh injected sample solution and system suitability requirements were measured for the standard preparation.

\section{Filter compatibility}

Filter compatibility was performed for nylon $0.2 \mu$ syringe filter (Pall life sciences) and PVDF $0.2 \mu$ (Millipore) syringe filter. To confirm the filter compatibility in proposed method, filtration recovery experiments were carried out by sample filtration technique. The working concentration level impurity standard was added to pre-analyzed tablet sample in duplicate. Spiked impurity samples were filter through both syringe filter and percentage difference was calculated against centrifuged sample.

\section{Results and Discussion}

\section{Method development and optimization}

The important criteria for development of successful RP-UPLC method for determination of aniline from the mesalamine drug product are: the method should be able to determine aniline in single run and it should be accurate, reproducible, robust, stability indicating, free of interference from blank/placebo/degradation product/other impurities and straightforward enough for routine use in quality control laboratory testing.

To develop the stability indicating method, first the retention behaviour of aniline compound with change in percentage of organic solvent (acetonitrile) and with change in $\mathrm{pH}$ of buffer was studied on Reprosil Gold100 C18-XBD column (50 mm x $2.0 \mathrm{~mm}, 1.8 \mu$ ). 1-octane sulphonic acid sodium salt ion pair reagent was used in buffer preparation to improve the peak shape and avoid the other substances co-elution at the same retention time in RP chromatography. The buffer $\mathrm{pH} 6.0$ was found more appropriate for robust peak shape and RT (retention time) performance of interested aniline substance. The final isocratic run was chosen with regards to the peak resolution and analysis time (total run time $5 \mathrm{~min}$ for one injection) as well. The flow rate of $0.5 \mathrm{~mL} / \mathrm{min}$ was optimized with regard to the back pressure and analysis time as well. Detection wavelength $200 \mathrm{~nm}$ was selected for aniline due to higher detector response at this nm. Diluent was optimised based on solubility of aniline and mesalamine.

\section{Analytical parameters and validation}

After satisfactory development of method it was subjected to method validation as per ICH guideline $^{26}$. The method was validated to demonstrate that it is suitable for its intended purpose by performing system suitability, accuracy, precision, linearity, robustness, ruggedness, solution stability, LOD, LOQ, filter compatibility and stability indicating capability. 


\section{System suitability}

The percentage RSD of area count of six replicate injections was below $2.0 \%$. The results of system suitability are presented in Table 1 . Low values of \% RSD of replicate injections indicate that the system is precise. Results of other system suitability parameters such as capacity factor, tailing factor, similarity factor (between two standard preparation) and theoretical plates are presented in Table 1. As seen from this data, the acceptable system suitability parameters are: relative standard deviation of replicate injections is not more than 1.5 , similarity factor should be in between 0.9 to 1.1 and theoretical plates are not less than 5000. Overlay chromatogram of replicate standard injections are presented in Figure 2. Results of system suitability parameters from different studies are presented in Table 1.

Table 1. System suitability results

\begin{tabular}{lccccc}
\hline \multicolumn{1}{c}{ Condition } & $\begin{array}{c}\text { USP tailing } \\
\text { factor }\end{array}$ & $\begin{array}{c}\text { USP } \\
\text { theoretical } \\
\text { plates }\end{array}$ & $\begin{array}{c}\text { Capacity } \\
\text { factor }\end{array}$ & $\begin{array}{c}\text { Similarity } \\
\text { factor of } \\
\text { standard }\end{array}$ & $\begin{array}{c}\text { \% RSD of } \\
\text { standard } \\
\text { area }\end{array}$ \\
\hline Precision & 1.06 & 7643 & 9.2 & 1.02 & 1.5 \\
Intermediate precision & 1.06 & 7825 & 9.2 & 1.03 & 1.2 \\
At $0.45 \mathrm{~mL} /$ min flow rate & 1.10 & 7596 & 10.3 & 0.96 & 0.9 \\
At $0.55 \mathrm{~mL} /$ min flow rate & 1.10 & 8386 & 8.3 & 0.97 & 1.7 \\
At $45^{\circ} \mathrm{C}$ column oven temp. & 1.13 & 7411 & 9.7 & 1.01 & 0.8 \\
At $55^{\circ} \mathrm{C}$ column oven temp. & 1.04 & 7704 & 8.8 & 0.98 & 0.9 \\
With buffer pH 5.9 & 1.03 & 7740 & 9.2 & 1.02 & 1.2 \\
With buffer pH 6.1 & 1.12 & 7799 & 9.2 & 1.01 & 1.3 \\
\hline
\end{tabular}

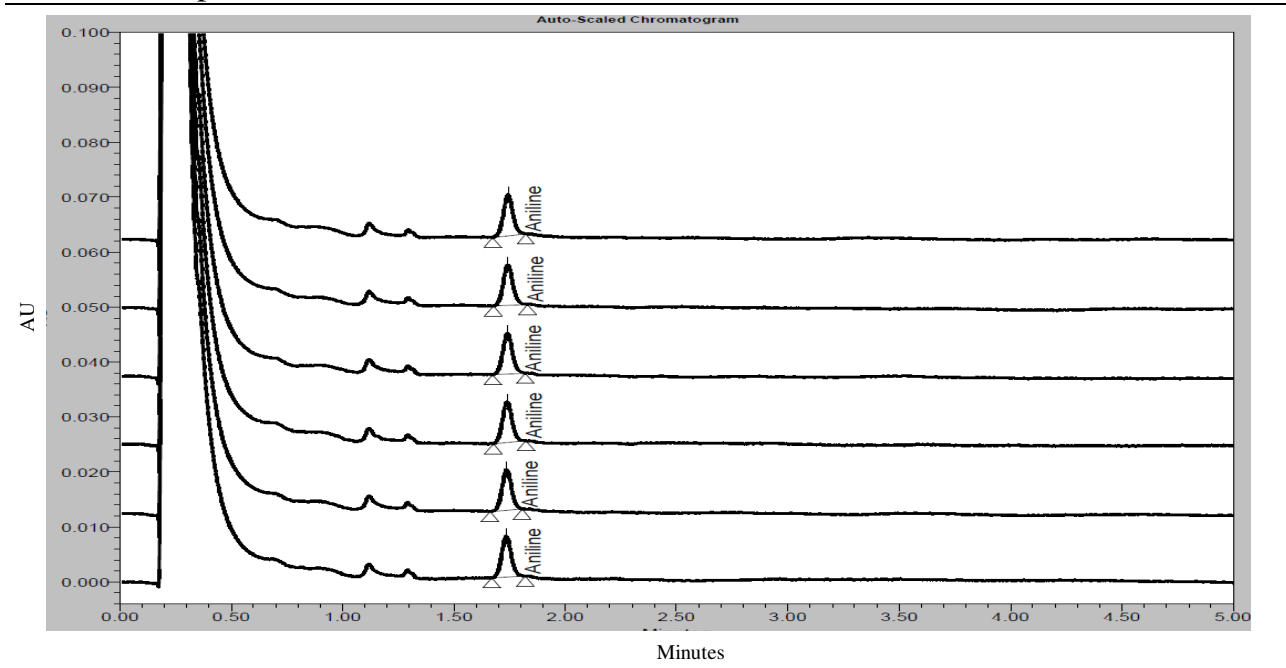

Figure 2. Overlay chromatograms of replicate standard injections.

\section{Specificity}

Typical overlaid chromatograms are presented in Figure 3, which show separation of aniline compound from blank and placebo. No interference was observed at the RT of aniline due to blank and placebo. In all the degradation conditions, no interference was observed at the RT of aniline. It indicates that method is specific for the aniline substance in mesalamine drug product. Therefore, the method is specifics and suitable for routine work. The standard chromatogram with its 3D plot and purity plot is presented in Figure 4. 


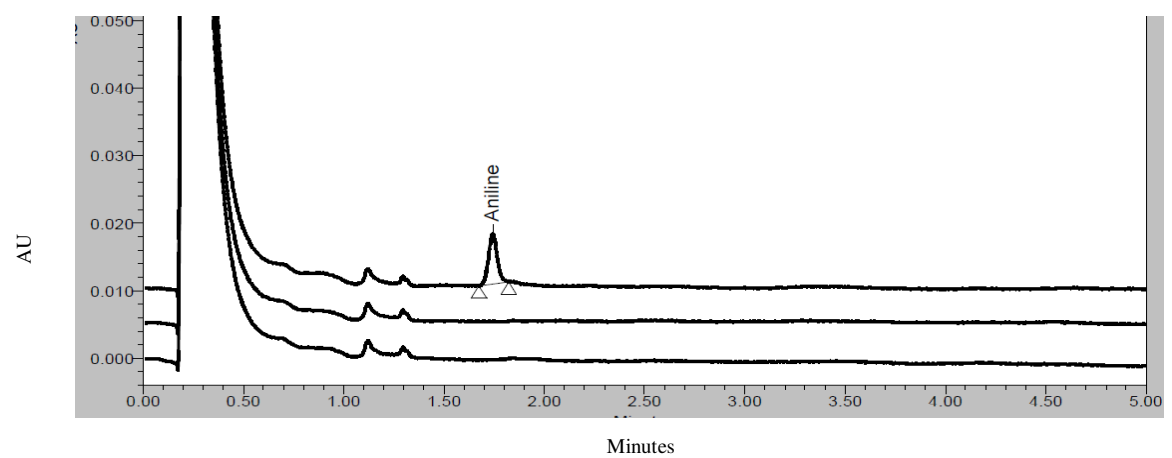

Figure 3. Overlay chromatogram of blank (bottom), placebo (middle) and standard preparation (top)
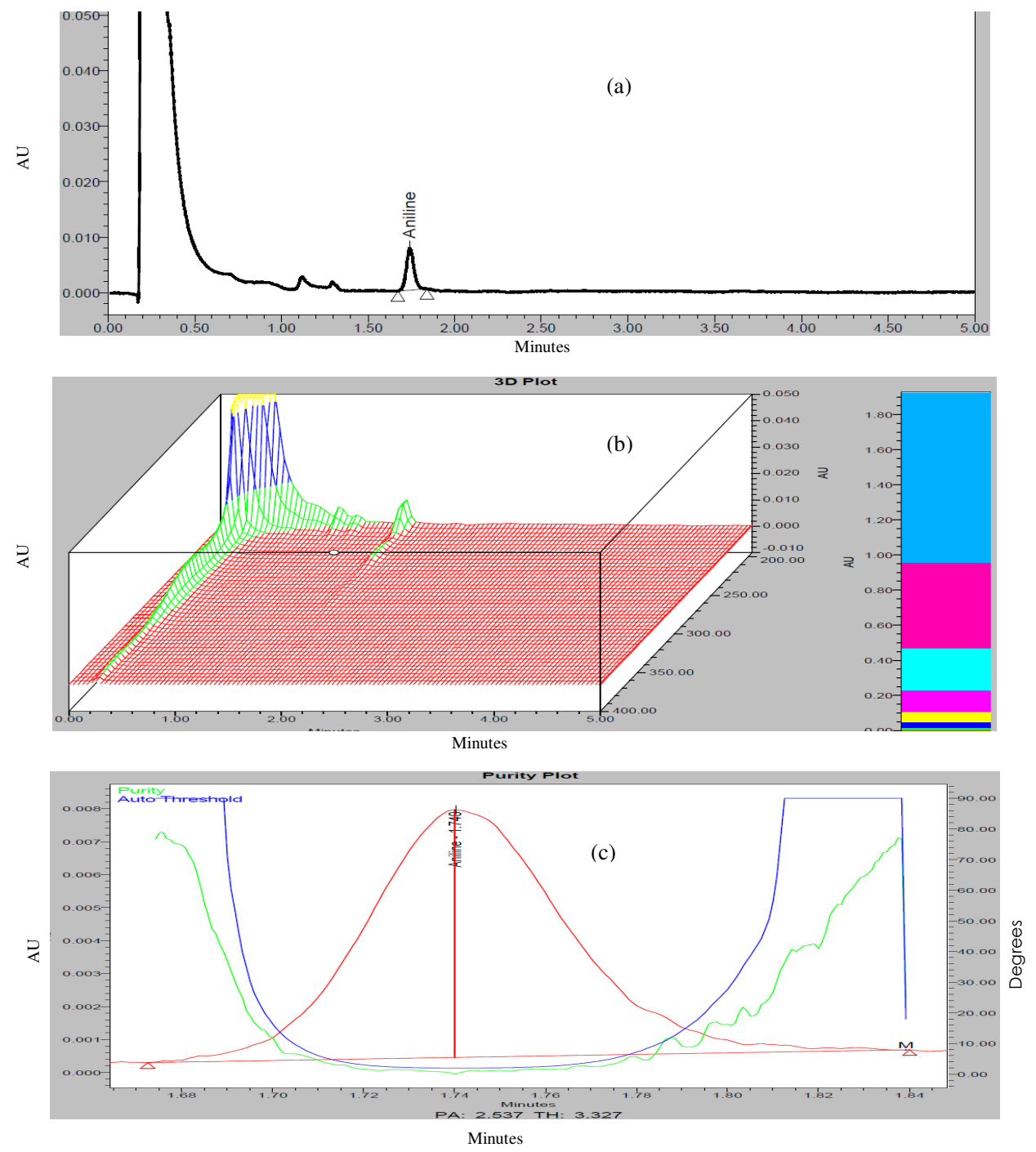

Figure 4. (a) Standard chromatogram (b) 3D plot and (c) purity plot 


\section{Precision}

The average \% impurity ( $\mathrm{n}=6)$ and $\%$ RSD results are shown in Table 2. Precision (at LOQ and at $100 \%$ level) results are shown in Table 2 along with intermediate precision data. Low values of RSD, indicates that the method is precise. Overlay chromatograms of precision at LOQ and precision at $100 \%$ are presented in Figure 5 and 6.

Table 2. Precision at LOQ, precision at $100 \%$ and intermediate precision results ${ }^{@}$

\begin{tabular}{ccccccc}
\hline Impurity & Precision at LOQ & \multicolumn{2}{c}{ Precision at $100 \%$} & \multicolumn{2}{c}{$\begin{array}{c}\text { Intermediate } \\
\text { precision }\end{array}$} \\
\cline { 2 - 7 } & \%impurity & \%RSD* & \%impurity & \%RSD* & \%impurity & \%RSD* \\
\hline Aniline & 0.00005591 & 1.98 & 0.0005253 & 0.75 & 0.0005136 & 0.97 \\
\hline
\end{tabular}

${ }^{\#}$ Average of six determinations, *Determined on six values, ${ }^{\circledR}$ Demonstrated by spiking known impurities into sample.

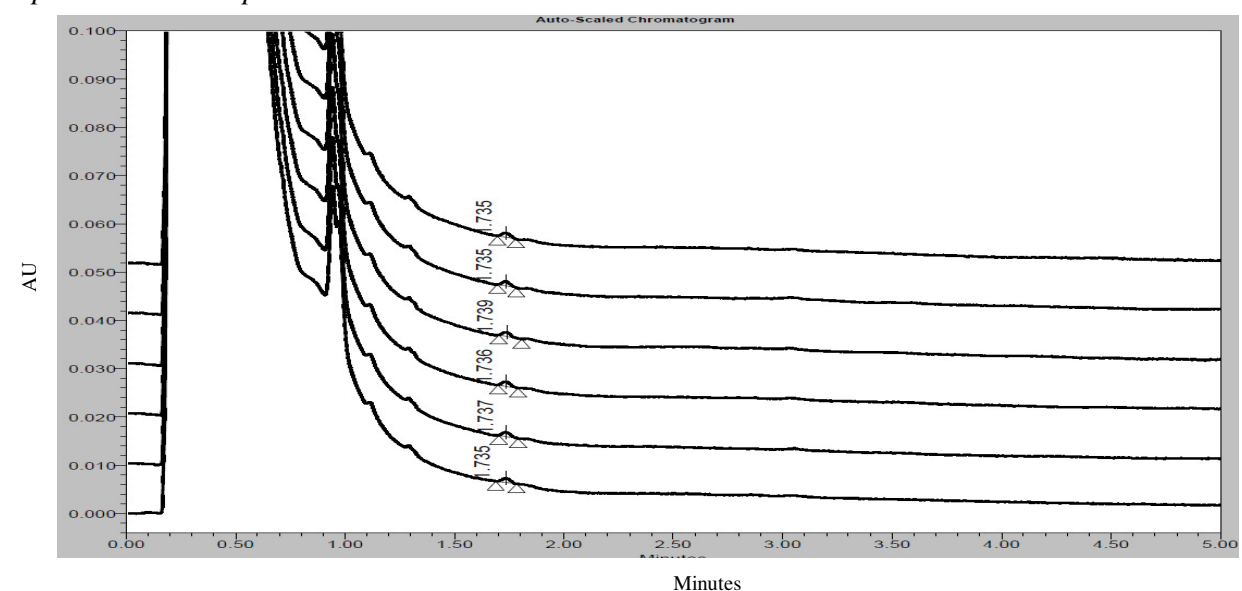

Figure 5. Overlay chromatograms of precision at LOQ level

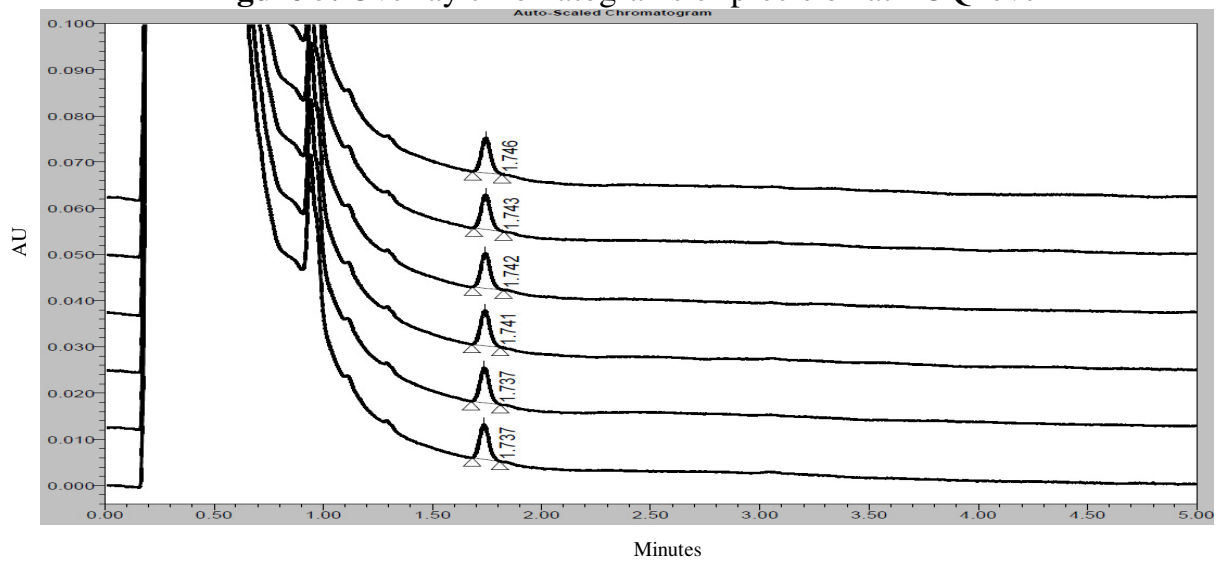

Figure 6. Overlay chromatograms of precision at $100 \%$ level

Accuracy by recovery

The accuracy by recovery was performed on aniline impurity, from LOQ to $150 \%$ of standard concentration. Recovery of aniline was performed in triplicate for each level. 
The results of recoveries (LOQ, 50\%, 70\%, 100\%, 130\% and 150\%) for aniline are shown in Table 3 . The amount recovered was within $\pm 10 \%$ of amount added which indicates that the method is accurate and also there is no interference due to excipients present in the tablets. Overlay chromatograms of accuracy are presented in Figure 7.

Table 3. Accuracy results for aniline

\begin{tabular}{ccccccc}
\hline & \multicolumn{7}{c}{ Recovery (With triplicate determination at each level) } \\
\cline { 2 - 7 } Aniline & at LOQ & at 50\% & at 70\% & at 100\% & at 130\% & at $150 \%$ \\
\hline Mean \% & 106.75 & 102.24 & 98.20 & 99.42 & 97.14 & 97.04 \\
\% R.S.D* & 0.96 & 1.14 & 1.57 & 0.50 & 0.76 & 0.11 \\
\hline
\end{tabular}

* Determined on three values

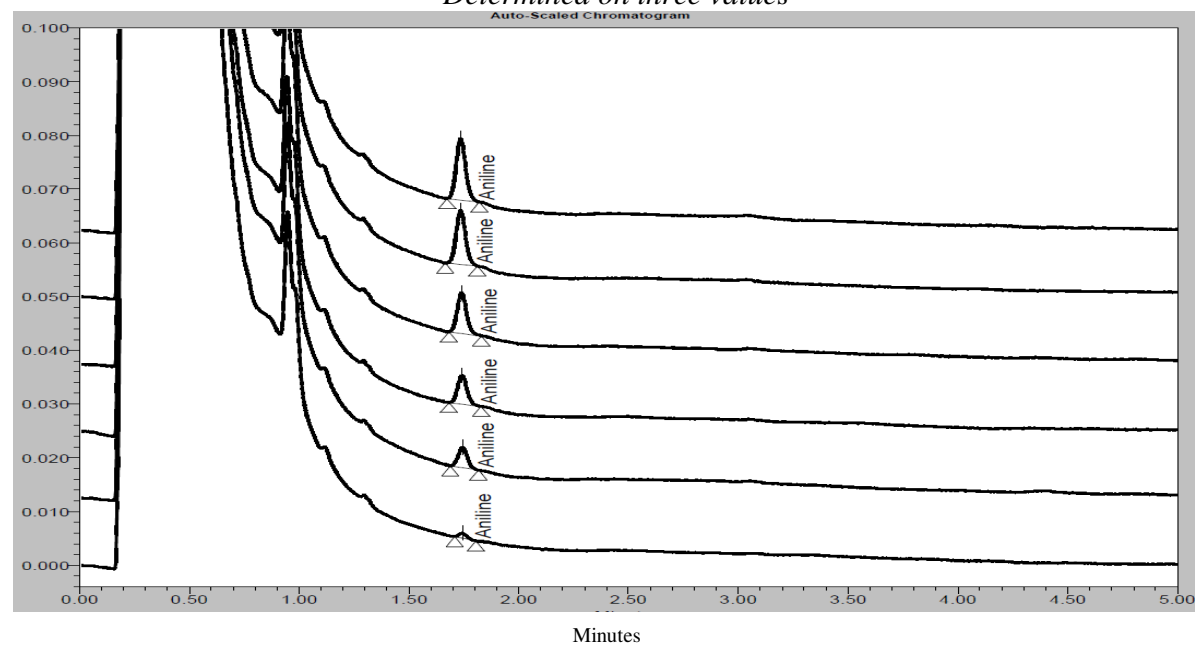

Figure 7. Overlay chromatogram of accuracy study at LOQ, 50, 70, 100, 130 and 150\%.

\section{$L O D$ and $L O Q$}

The concentration (in $\mu \mathrm{g} / \mathrm{mL}$ ) with signal to noise ratio of at least 3 was taken as LOD and concentration with signal to noise of at least 10 was taken as LOQ, which meets the criteria defined by ICH guidance ${ }^{26}$. The LOD and LOQ result of aniline substance is presented in Table 4.

Table 4. Limit of detection and limit of quantification

\begin{tabular}{cccc}
\hline Aniline & Concentration $(\mathrm{ng} / \mathrm{mL})$ & \% Impurity (w.r.t. 5-ASA) & Signal to Noise Ratio \\
\hline LOD & 5.5 & 0.000018 & 2.9 \\
LOQ & 18 & 0.00006 & 10.4 \\
\hline
\end{tabular}

\section{Linearity}

The response was found linear for aniline from LOQ to $150 \%$ of standard concentration. This test was performed on seven different levels of aniline solution, which gave us a good confidence on analytical method with respect to linear range. For aniline substance the correlation coefficient was greater than 0.999. Correlation coefficients and linearity equations of impurity and $\mathrm{Y}$ - intercept bias are presented in Table 5. Linearity curve is presented in Figure 8 and overlay linearity chromatograms are presented in Figure 9. 
Table 5. Linearity results (determined on LOQ, 25, 50, 75, 100, 125 and 150\%)

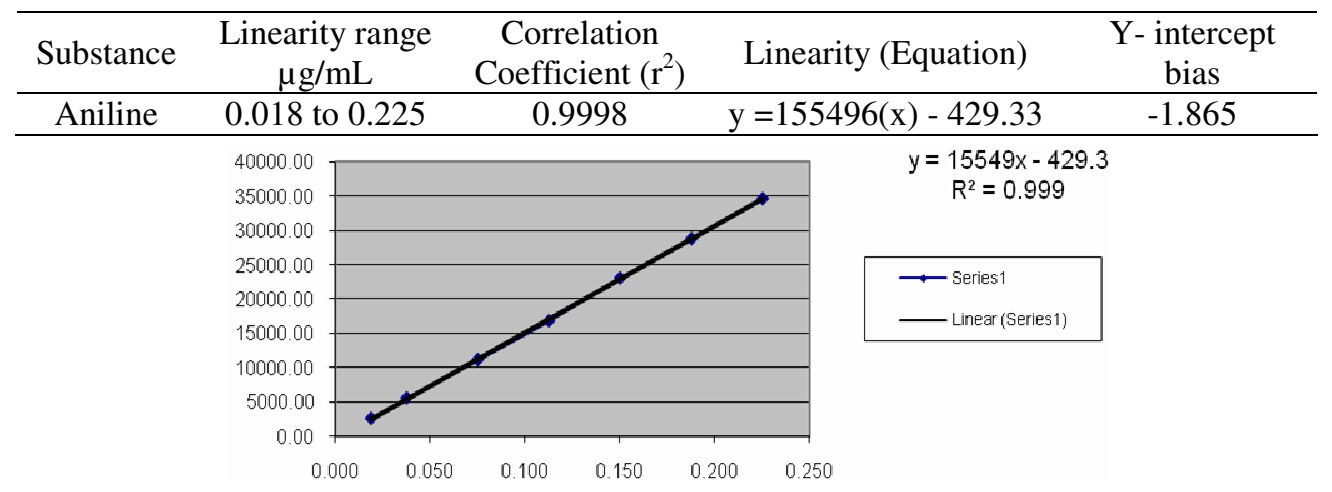

Figure 8. Linearity curve of aniline impurity

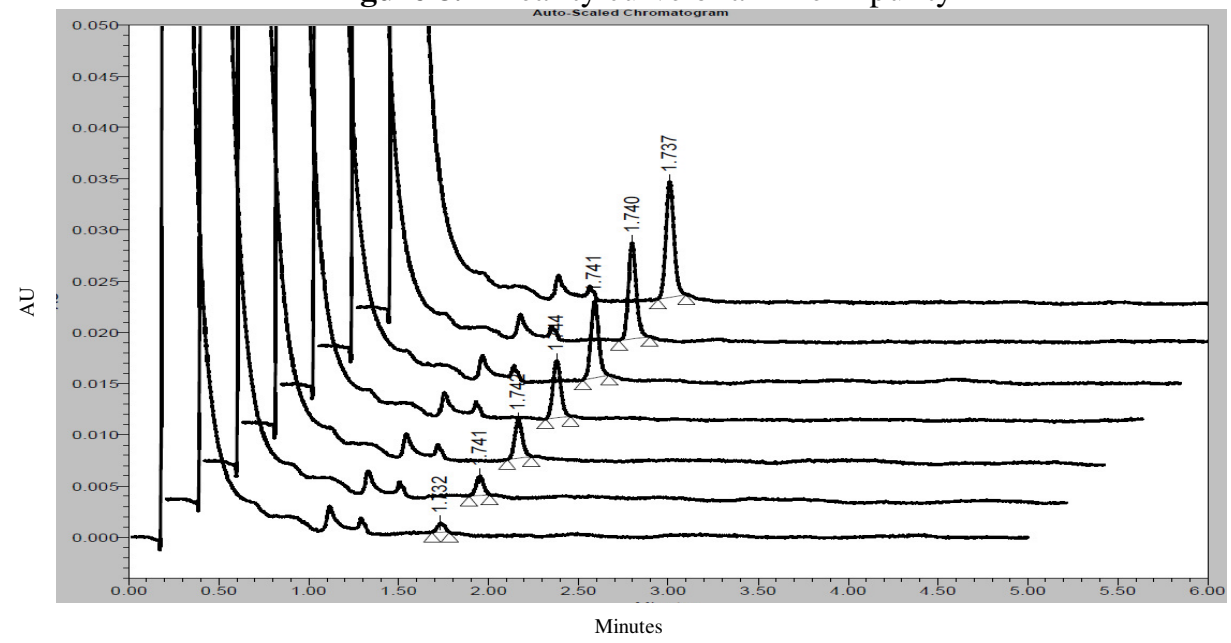

Figure 9. Overlay chromatograms of aniline linearity (LOQ to $150 \%$ )

\section{Robustness}

No significant effect was observed on system suitability parameters such as tailing factor, capacity factor and theoretical plates of respective component, when small but deliberate changes were made to chromatographic conditions. The results are presented in Table 1 along with system suitability parameters. No significant effect was observed on retention time (RT) of impurity, when deliberate changes were made to chromatographic condition. Thus, the method was found to be robust with respect to variability in variable conditions.

\section{Stability of standard and sample solution}

Sample solution did not show any appreciable change in impurity value when stored at ambient temperature up to $20 \mathrm{~h}$. Percentage impurity result of $9 \mathrm{~h}$ and $20 \mathrm{~h}$ was compared with freshly prepared sample solution. Percentage difference in impurity was calculated with respect to freshly injected sample solution. Results are presented in Table 6. Standard solution did not show any unknown peak during this $20 \mathrm{~h}$ study and also fulfil the requirements of system suitability. Standard solution stability results are presented in Table 7. 
Table 6. Sample solution stability results

\begin{tabular}{|c|c|c|c|c|c|c|c|c|c|c|}
\hline \multirow{3}{*}{ Impurity } & Initia & Sample & \multicolumn{4}{|c|}{ Sample after 9 hours } & \multicolumn{4}{|c|}{ Sample after 20 hours } \\
\hline & \multicolumn{2}{|c|}{ Imp. in $\%$} & \multicolumn{2}{|c|}{ Imp. in $\%$} & \multicolumn{2}{|c|}{ Difference in $\%$} & \multicolumn{2}{|c|}{ Imp. in \% } & \multicolumn{2}{|c|}{ Difference in $\%$} \\
\hline & Sam-1 & Sam-2 & Sam-1 & Sam-2 & Sam-1 & Sam-2 & Sam-1 & Sam-2 & Sam-1 & Sam-2 \\
\hline Aniline & 0.000505 & 0.000502 & 0.000506 & 0.000500 & 0.000001 & 0.000002 & 0.000496 & 0.000498 & 0.000009 & 0.000004 \\
\hline
\end{tabular}

Table 7. Standard solution stability results

\begin{tabular}{ccccccc}
\hline \multirow{2}{*}{ Substance } & \multicolumn{2}{c}{ Initial } & \multicolumn{2}{c}{ After 9 h. } & \multicolumn{2}{c}{ After 20 h. } \\
\cline { 2 - 7 } & Area & \%RSD & Area & \%RSD* & Area & \%RSD \\
\hline Aniline & 22449 & 0.78 & 22246 & 0.79 & 22356 & 0.73 \\
\hline
\end{tabular}

${ }^{*}$ Determined on five replicate injections, *Determined on five initial and $9 \mathrm{~h}$ standard injections, (\% RSD of six inj.) ${ }^{\circledR}$ Determined on five initial, $9 \mathrm{~h}$ and $20 \mathrm{~h}$ standard injections. (\% RSD of seven inj.)

\section{Filter compatibility}

Filter compatibility of PVDF and nylon syringe filter $(0.2 \mu)$ was performed on duplicate sample preparation. Filtered sample solution was not shows any significant changes in aniline percentage with respect to centrifuged samples. Difference in impurity percentage result was presented in Table 8 . In displayed result difference in $\%$ of impurity was not observed more than $0.000007 \%$, which indicates that both syringe filter having a good compatibility with sample solution. Overlay chromatograms are presented in Figure 10.

Table 8. Filter compatibility results

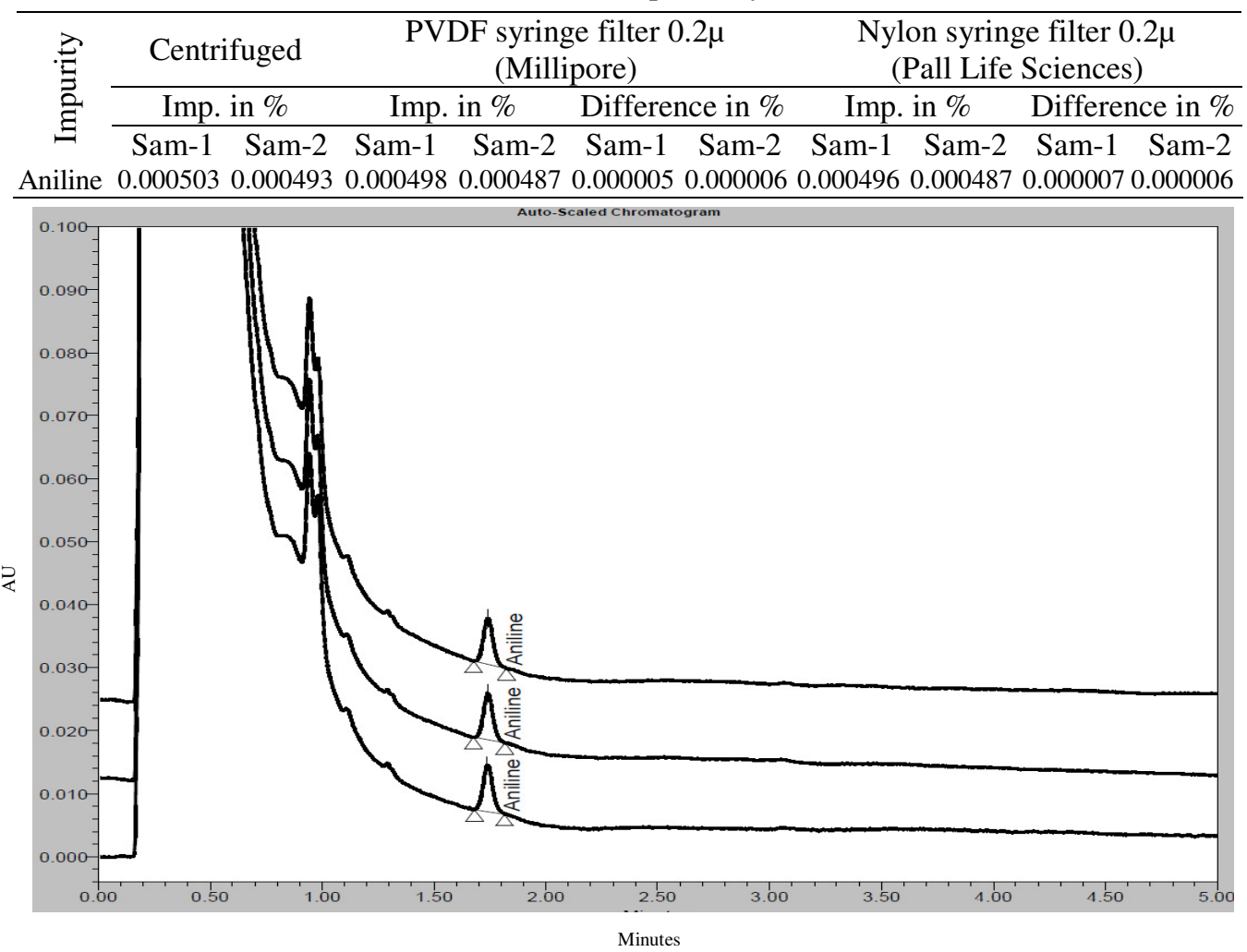

Figure 10. Overlay chromatograms of centrifuge, nylon and PVDF filtered sample 


\section{Conclusion}

A novel RP-UPLC method was successfully developed and validated for determination of aniline impurity from mesalamine drug product. The total run time was $5 \mathrm{~min}$, within which drug and their degradation products were separated from aniline. Method validation results have proved that the method is selective, precise, accurate, linear, rugged, robust and stability indicating with low LOD and LOQ. Sample solution stability and filter compatibility was also established. This method can successfully be applied for routine analysis and stability study of mesalamine delayed release drug product. Thus, the method provides high throughput solution for determination of aniline in the mesalamine delayedrelease formulation with excellent selectivity, precision and accuracy. This method can also be applied for quantifying the trace levels of aniline from drug substances, drug products and different type of samples.

\section{Acknowledgment}

The authors would like to thank M/s Dr. Reddy's Laboratories Ltd. for supporting this work. Authors also would like to acknowledge Mr. Amit R. Kharkar for his immense support. All the development and validation work was performed at Analytical Research and Development (AR\&D) Lab., Dr. Reddy's Laboratory Ltd., IPDO, Bachupally, Hyderabad, India.

\section{References}

1. Gisbert J P, Gomollon F, Mate J and Pajares J M, A Systematic Review Dig Dis Sci., 2002, 47, 471-488.

2. Klotz U, Eur J Clin Pharmacol., 2000, 56, 353-362.

3. De Vos M, Clin Pharmacokinetics, 2000, 39, 85-97.

4. Pappercorn M A and Goldman P, Gestroenterology, 1973, 64(2), 240-245.

5. Haagen Nielsen O and Bondesen S, Br J Clin Pharmacol., 1983, 16(6), 738-740.

6. Schröder H, Compbell D E S, Clin Pharmacol Ther., 1972, 13(4), 539-551.

7. Goodman and Gilman's, The Pharmacological Basis of Therapeutics, $8^{\text {th }}$ Ed., Pergamon, 1990, p.650.

8. Reynolds J F, (31 ${ }^{\text {st }}$ Ed.,) Martindale, The Extra Pharmacopoeia., Royal Pharmaceutical Society, London, 1996, p.1227.

9. Genotoxic and Carcinogenic impurities in drug Substances and Products: Recommended approaches. FDA Centre for Drug Evaluation and Research Guidance for Industries (Draft), 03 December 2008.

10. Ernst M. Bomhard and Bernd A. Herbold., Critical Reviews in Toxicology, 2005, 35(10), 783-835.

11. Ken-ichi Masumura, Yukari Totsuka, Keiji Wakabayashi and Takehiko Nohmi., Carcinogenesis, 2003, 24(12), 1985-1993.

12. Toshihiko Kawamori, Yukari Totsuka, Naoaki Uchiya, Tomohiro Kitamura, Hideyuki Shibata, Takashi Sugimura and Keiji Wakabayashi., Carcinogenesis, 2004, 25(10), 1967-1972.

13. Meiping Zhao, Xinxiang Zhang, Yuanzong Li and Wenbao Chang, Anal Lett., 2000, 33(14), 3067-3075.

14. Rahim S A, Nada D. Ismail and Bashir W A, Microchimica Acta, 1986, III, 417-423.

15. Zhao X and Suo Y, J Separ Sci., 2008, 31(4), 646-658.

16. Xiao-Lan Chen, Zhong-Bao Li, Ya-Xian Zhu and Jin-Gou Xu, Anal Chim Acta, 2004, 505(2), 283-287. 
17. Jun Ping Xiao, Qing Xiang Zhou, Xiao Ke Tian, Hua Hua Bai and Xian Fa Su, Chin Chem Lett., 2007, 18(6), 730-733.

18. John McDonald, Andrew Mc Intyre, Michael L. Hitchman and David Littlejohn, Appl Spectrosc, 1998, 52(6), 908-911.

19. Cheing-Tong Yan and Jen-Fon Jen, J Chromatographia, 2004, 59(7-8), 517-520.

20. Liu X., Spectroscopy and Spectral Analysis, 2006, 26(6), 1141-1144.

21. Sarafraz Yazdi A and Es'haghi Z, J Chromatographia, 2006, 63(11-12), 563-569.

22. Reig, N. Calaf, R. E. Messegure, A. Morato, A. Escabros, J. Gelpi, E. Abian., J Mass Spectrom., 2007, 42(4), 527-541.

23. Mortensen S K, Trier X T Foverskov A and Petersen, J Chromatogr A., 2005, 1091(1-2), 40-50.

24. United States Pharmacopeia, USP32-NF27, p.2894.

25. British Pharmacopeia, BP- 2010, p.1368.

26. ICH, Validation of Analytical Procedure, Text and Methodology Q2(R1), International Conference on Harmonization, IFPMA, Geneva, 2005. 


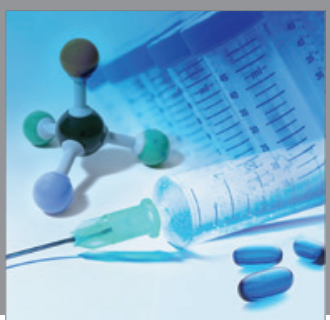

International Journal of

Medicinal Chemistry

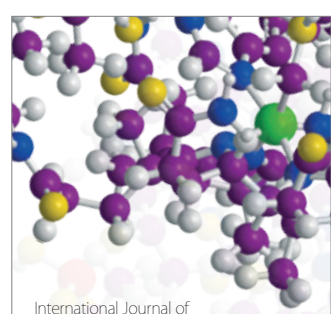

Carbohydrate Chemistry

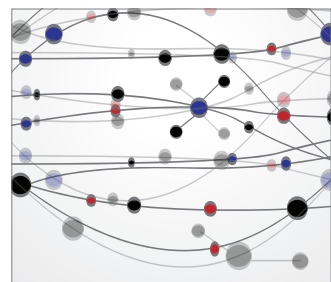

The Scientific World Journal
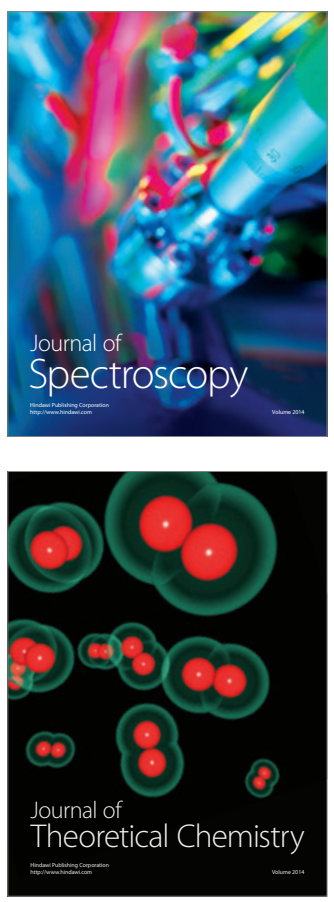
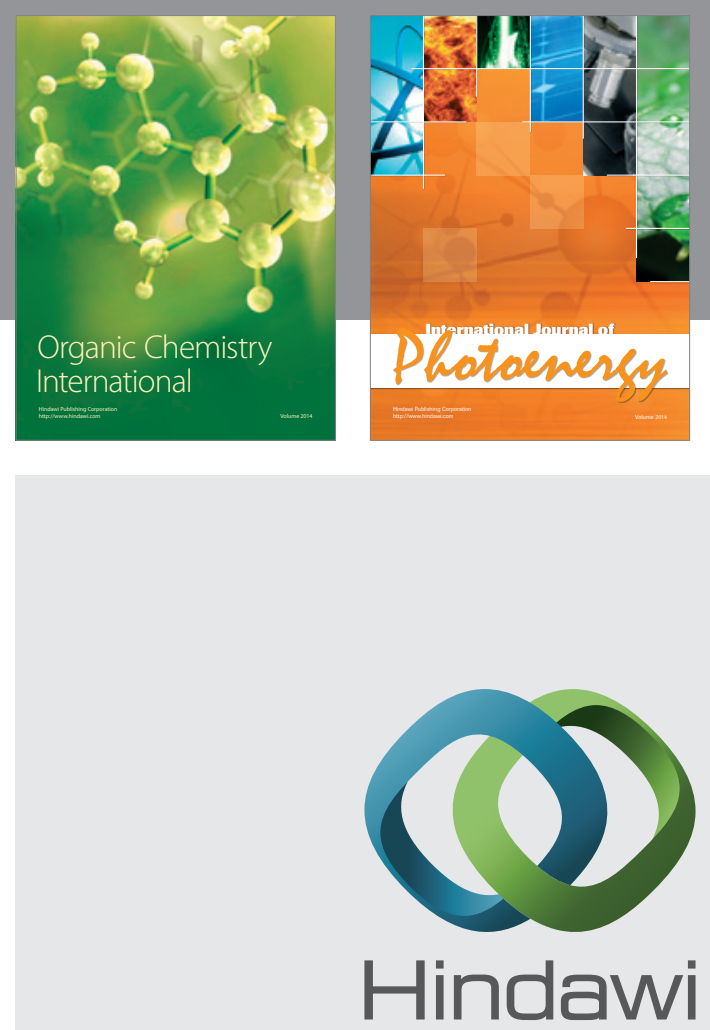

Submit your manuscripts at

http://www.hindawi.com
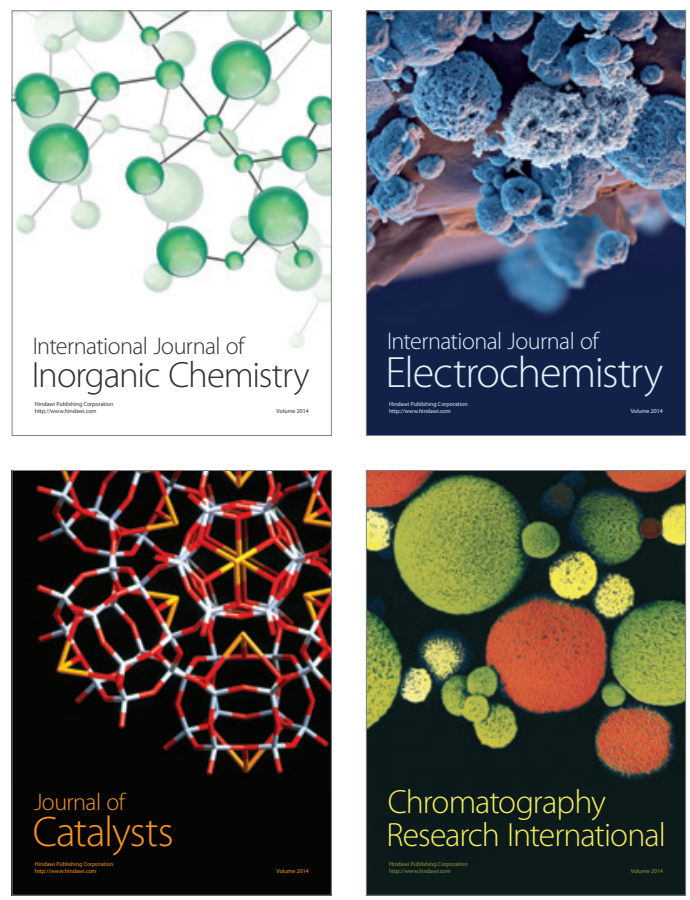
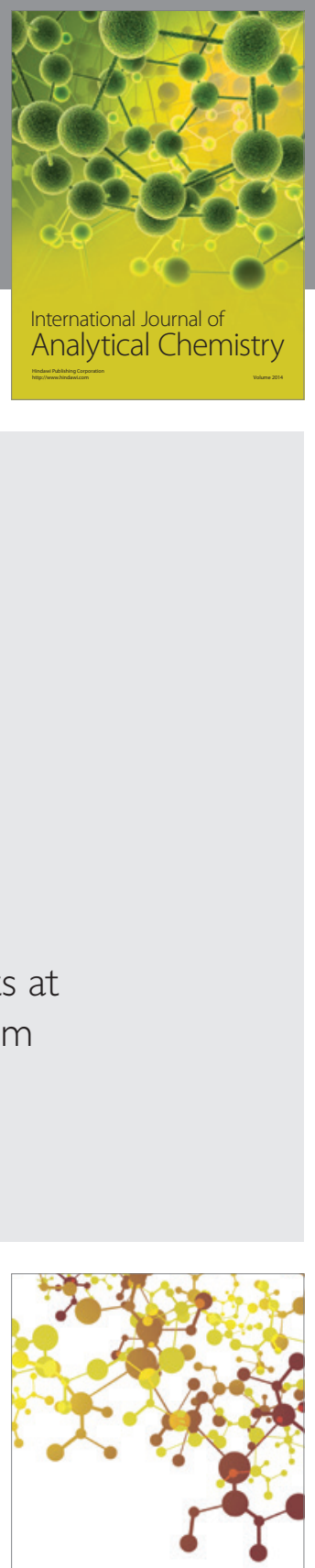

Journal of

Applied Chemistry
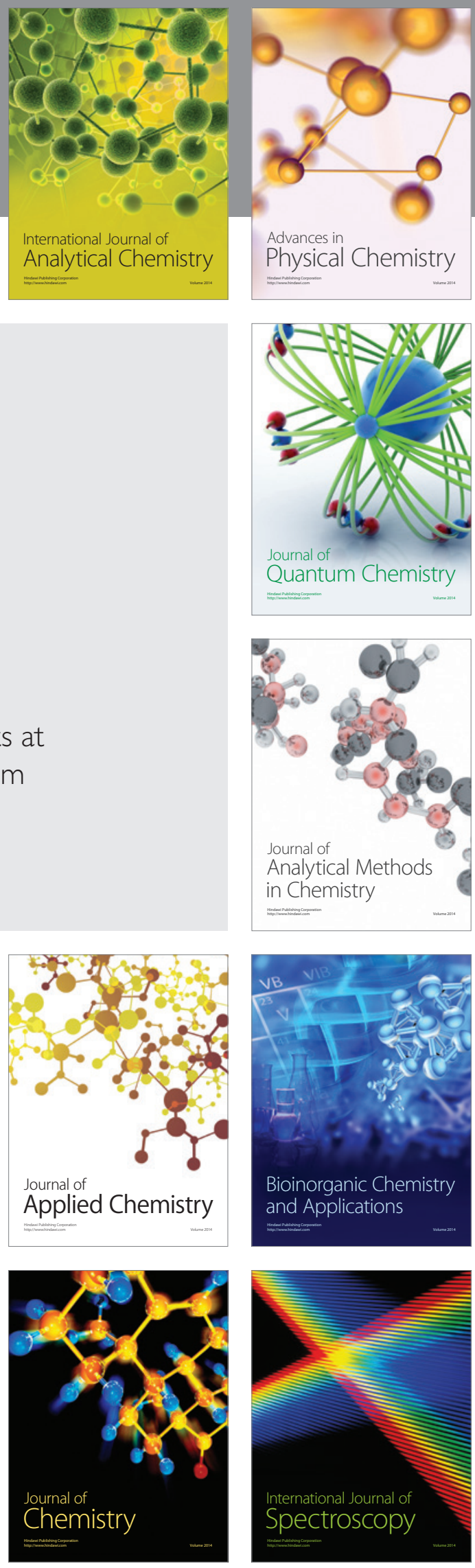